Para enlazar con este artículo / To link to this article:

http://dx.doi.org/10.6035/MonTI.2019.11.6

Para citar este artículo / To cite this article:

Mendoza Domínguez, Nuria \& Anna Matamala. (2019) "Panorama de la enseñanza de la audiodescripción en España: Resultados de un cuestionario." In: Tolosa Igualada, Miguel \& Álvaro Echeverri (eds.) 2019. Porque algo tiene que cambiar. La formación de traductores e intérpretes: Presente \& futuro / Because something should change: Present $\&$ Future Training of Translators and Interpreters. MonTI 11, pp. 155-185.

\title{
PANORAMA DE LA ENSEÑANZA DE LA AUDIODESCRIPCIÓN EN ESPAÑA: RESULTADOS DE UN CUESTIONARIO ${ }^{1}$
}

\author{
Nuria Mendoza Domínguez \\ nuria.mendozad@e-campus.uab.cat \\ Universidad Autónoma de Barcelona \\ nmendoza@nebrija.es \\ Universidad Nebrija
}

Anna Matamala

Anna.Matamala@uab.cat Universidad Autónoma de Barcelona

\section{Resumen}

La audiodescripción (AD) consiste en la conversión de imágenes a palabras para ofrecer una alternativa a los contenidos visuales a quienes no pueden acceder a estos. Puede considerarse como un tipo de traducción intersemiótica y como tal, está frecuentemente incluida en los currícula de traducción audiovisual y en los estudios de accesibilidad a los medios. Sin embargo, los estudios sobre didáctica de la audiodescripción son casi

1. Este trabajo de investigación ha recibido el apoyo de ADLAB PRO (Audiodescripción: Un laboratorio para el desarrollo de un nuevo perfil profesional), proyecto Erasmus+ financiado por la Unión Europea, Acción Clave 2 - Alianza Estratégica (2016-1-IT02KA203-024311). La primera autora está actualmente afiliada al Programa de Doctorado en Traducción y Estudios Interculturales de la Universitat Autònoma de Barcelona. La segunda autora forma parte de TransMedia Catalonia, grupo de investigación financiado por la Generalitat de Cataluña (2017SGR113). La información y los puntos de vista volcados en esta publicación son los de las autoras y no reflejan necesariamente la opinión oficial ni de la Unión Europea ni de otras instituciones. Ni las instituciones ni los órganos de la Unión Europea ni ninguna persona que actúe en su nombre pueden ser considerados responsables del uso que pueda hacerse de la información contenida en ellos. Damos las gracias a todos aquellos que participaron en el cuestionario, sin quienes este estudio no hubiera sido posible. 
inexistentes. Este trabajo presenta los resultados de un cuestionario cuyo objetivo es obtener un panorama actual de la enseñanza de la audiodescripción en España. Analiza los resultados de los 27 participantes españoles que respondieron al cuestionario, desarrollado como parte de ADLAB PRO, un proyecto Erasmus+ financiado por la Comisión Europea. Su objetivo fundamental es crear material didáctico para la formación de los audiodescriptores. Para poder contextualizar esta investigación, el artículo explica cómo se aborda la didáctica de la audiodescripción en España.

\begin{abstract}
"Audio description training in Spain: a survey-based overview of teaching practices"

Audio description is a translation of images into words aiming to provide an alternative to the visual content for those who cannot access it. It can be considered an intersemiotic translation and, as such, it has often been taught as part of courses in audiovisual translation and media accessibility studies. However, studies on the specifics of the didactics of audio description are missing. This article presents the results of a questionnaire aiming to map the current situation regarding the teaching of audio description in Spain. It reports on the results obtained from 27 Spanish participants that answered a questionnaire developed as part of ADLAB PRO, an Erasmus+ project funded by the European Commission whose ultimate goal is to create didactic material for the training of audio describers. In order to contextualize such research, the article also provides an overview of the didactics of audio description in Spain.
\end{abstract}

Palabras clave: Audiodescripción. Didáctica de la traducción. Traducción audiovisual. Accesibilidad a los medios. ADLAB PRO.

Keywords: Audio description. Translation didactics. Audiovisual translation. Media accessibility. ADLAB PRO. 


\section{Introducción}

La accesibilidad en España era hace aproximadamente quince años una asignatura pendiente desde todos los puntos de vista. En el caso de la audiodescripción (AD), los audiodescriptores eran en su mayoría voluntarios y los cursos universitarios sobre AD eran escasos, ya que no había una demanda comercial. Tampoco había un reconocimiento social, legal ni profesional del sector (Orero 2005a). El año 2003 fue clave para el desarrollo en temas de accesibilidad porque se erigió en el Año Europeo de las Personas con Discapacidad. Ese hecho impulsó acciones como el Congreso Europeo sobre Medios de Comunicación y Discapacidad en ese mismo año en Atenas. Igualmente, en España el Ministerio de Trabajo y Asuntos Sociales aprobó en 2004 el I Plan de Accesibilidad "Diseño para todos". En él, el tema de la accesibilidad audiovisual aparecía en el análisis de problemas detectados. Entre otras medidas, se señalaron estrategias de concienciación, de formación y de inserción en los diseños universitarios que contemplaban ya entonces el desarrollo de material didáctico adecuado como una medida paralela. Hubo más acciones clave en esos años que sentaron las bases actuales de avance en accesibilidad: también en 2003 se consiguió un respaldo legal más con la ley 51/2003 de Igualdad de Oportunidades, No discriminación y Accesibilidad. Finalmente, en cuanto a la AD, en 2005 la culminación en España fue la creación de la norma UNE 153020:2005. En resumen, todos estos documentos, leyes, estándares, directrices europeas así como programas nacionales contribuyeron al incremento de la proyección social y política de la accesibilidad en la universidad (Orero 2005b).

En España el tema de la accesibilidad audiovisual, investigado en el marco de los estudios de traducción audiovisual (TAV), ha despertado un interés creciente en los últimos diez años. No obstante, en lo referente a las aproximaciones didácticas, en especial en el ámbito de la audiodescripción, la bibliografía puede considerarse todavía escasa, quizás porque esta sigue siendo todavía un terreno reciente y relativamente novedoso (Cerezo Merchán 2013). Es en este contexto en el que se sitúa la investigación que aquí presentamos. Nuestro objetivo es observar panorámicamente qué perfiles docentes enseñan $\mathrm{AD}$ en España y en qué tipo de cursos, así como qué destrezas son 
fundamentales en la formación de los audiodescriptores. Para ello analizaremos los resultados de los participantes españoles de un cuestionario desarrollado en el marco de ADLAB PRO, un proyecto Erasmus+ financiado por la Comisión Europea (ADLAB PRO n.d.).

Comenzaremos el artículo ofreciendo una visión panorámica de las contribuciones científicas que han estudiado audiodescripción y docencia. A continuación, describiremos el proyecto ADLAB PRO, en el que se enmarca la investigación que aquí se presenta, y seguidamente detallaremos la metodología usada para el estudio. En el apartado 5 se expondrán los resultados de la investigación, para concluir con unas consideraciones generales y algunas indicaciones sobre posibles vías de investigación futuras.

Es importante destacar que entendemos la AD como una traducción intersemiótica en la que las imágenes se convierten en palabras. Dicha traducción intersemiótica puede realizarse sobre un producto creado en la misma lengua que la AD (por ejemplo, audiodescripción en español de una película en español) o sobre un contenido previamente traducido interlingüísticamente (por ejemplo, audiodescripción en español de una película inglesa doblada al español).

\section{La didáctica de la audiodescripción}

El aumento en proyección y en visibilidad de la accesibilidad se demuestra en parte por medio del debate abierto sobre las competencias profesionales que debe poseer el audiodescriptor. El inicio de ese debate se remonta a más de diez años atrás, cuando comenzaron a realizarse estudios detallados sobre AD y docencia, que resumimos en los párrafos siguientes.

Matamala (2006) analizó el papel que debe jugar la universidad en la concienciación sobre la adquisición de competencias traductoras y lingüísticas tanto para la AD como para el subtitulado para sordos (SPS). En el artículo se recopilaron guías ya existentes en otros países y en España (la norma UNE 153020:2005 acababa de aprobarse), así como opiniones de expertos en relación con los requisitos necesarios para audiodescribir y las competencias que debían obtener los profesionales del sector. Todos los agentes sin excepción incluían recomendaciones y orientaciones vinculadas al uso del lenguaje, tanto para la AD como para el SPS. Además, Matamala aludía a los requisitos más importantes señalados por la Audio Description Association (http://audiodescription.co.uk/), en los que también se incluían aspectos referentes al uso del lenguaje, tales como la capacidad de síntesis y dominio del vocabulario, y otros referidos a la claridad y la agradabilidad de la voz.

Matamala mencionaba a otros autores como Navarrete (2007), que afirmaba que el audiodescriptor debe poseer competencias literarias, o Snyder 
(2007, 2008), autor de un manual de referencia posteriormente (2014), para quien el dominio del lenguaje también es uno de los pilares de la $\mathrm{AD}$, a los que había que añadir la capacidad de observación, de edición y de locución. Además, este estudio resaltó el papel clave de la universidad como agente principal en el debate de la adquisición de las competencias lingüísticas y traductoras que deben poseer los audiodescriptores. En el terreno académico muchas de las iniciativas abordadas en el campo de la AD comenzaron en las facultades de traducción y de interpretación.

Otro estudio de envergadura sobre AD y docencia fue el de Díaz Cintas (2006). Del estudio extraemos que los centros educativos que impartían cursos sobre accesibilidad audiovisual hace diez años eran escasos. El debate académico sobre las competencias que debían adquirir los profesionales del área, tanto en SPS como en AD, era limitado igualmente. En la propuesta de competencias, Díaz Cintas partió de la base de que en el terreno de la accesibilidad audiovisual se debía preparar al estudiante y futuro profesional de cara a la realidad de la sociedad española a corto plazo. Díaz Cintas dividió las unidades de competencias en cuatro categorías: lingüísticas, temáticas o de contenido, tecnológicas y aplicadas y, por último, personales y generales.

Competencias lingüísticas

Conocer el propio idioma

Creatividad, sensibilidad lingüística

Edición de textos en lengua propia

Conocimiento de la lengua inglesa

Competencias temáticas o de contenido

Conocer sobre discapacidad y

accesibilidad

Conocer sobre el lenguaje/semiótica

fílmicos

Mercado laboral y la legislación de AD y SPS

Teoría y práctica de la $\mathrm{AD}$

Conocimiento sobre el teatro

Historia del Arte

\section{Competencias tecnológicas y aplicadas \\ Programas informáticos e Internet \\ Disposición para aprender software \\ Estrategias de documentación}

\author{
Competencias personales y generales \\ Amplia cultura general \\ Capacidad de análisis, síntesis e \\ interpretación \\ Rapidez en la relación de ideas \\ Razonamiento crítico \\ Flexibilidad laboral, presión temporal \\ Trabajo en equipo \\ Habilidades de intermediación
}

Destacamos el hecho de que Díaz Cintas anticipara la importancia de los avances tecnológicos y su influencia en el aumento de los servicios de AD y la necesidad de que los futuros audiodescriptores conocieran en profundidad el mundo virtual. El autor concluía la importancia de iniciar un debate serio sobre la adquisición de competencias de los audiodescriptores, condición obligatoria para que en los años posteriores los servicios de AD aumentaran, cuantitativa y cualitativamente. 
Otras propuestas relacionadas con la didáctica de la $\mathrm{AD}$ han abordado cómo debería diseñarse un curso de AD. En este sentido, Matamala y Orero (2007), tras revisar las competencias y habilidades que debería poseer un audiodescriptor, explicaban cómo se diseñó un módulo de $\mathrm{AD}$ dentro del máster de Traducción Audiovisual de la UAB. En el diseño se explicitaban las competencias y resultados del aprendizaje previstos, así como el desarrollo del curso, con ejercicios concretos. También en relación con la didáctica de la $\mathrm{AD}$, Basich Peralta et al. (2009) contextualizarían brevemente en su estudio el aprendizaje por competencias, señalando las competencias comunes para las profesiones de los audiodescriptores y de los traductores. En base a las coincidencias que presentan ambas profesiones, los autores abogaban por la inclusión de la AD en los programas universitarios de traducción, en lo que se refiere a las competencias, destrezas y conocimientos a adquirir. Por otra parte, estudios coetáneos sobre AD y didáctica (Remael \& Vercauteren 2007) reflexionaron sobre cómo las guías y normas existentes, si bien esenciales, no siempre dan respuesta a las preguntas de los audiodescriptores sobre qué elementos incluir en una AD determinada. A partir de esta premisa, los autores se propusieron demostrar cómo la narrativa fílmica puede ayudar a seleccionar la información visual y convertirse en herramienta didáctica útil en la enseñanza de la AD. También con un enfoque didáctico, Marzà Ibáñez (2010) presentó una propuesta de priorización y relevancia de la información visual a incluir en un trabajo audiodescriptivo, por medio de la narrativa fílmica. Una aportación clave de Marzà Ibáñez es su propuesta de criterios de evaluación en un contexto académico que permite, según la autora, reconciliar la subjetividad inherente a la AD con la sistematicidad que requiere la docencia.

Finalmente, nos gustaría mencionar otros estudios como el de Cambeiro Andrade et al. (2007), el de Reyes (2007), o los más recientes de Martínez Martínez (2012) y Álvarez de Morales Mercado (2017), que ha realizado una aplicación metodológica de la teoría socio-constructivista del aprendizaje con la elaboración y análisis de la $\mathrm{AD}$ de dos espacios arquitectónicos concretos en Granada.

Un enfoque distinto al que ocupa este artículo lo adoptan los autores que reflexionan sobre el uso de la $\mathrm{AD}$ como herramienta didáctica en la enseñanza de lenguas (Talaván 2018; Talaván et al. 2014) o en relación con la adquisición de vocabulario (Vermeulen \& Ibáñez Moreno 2013). A nivel más aplicado, se han publicado manuales en el mundo anglosajón (Fryer 2016; Snyder 2014), pero en el ámbito español no existe un manual dedicado exclusivamente a la enseñanza de la AD. Sí se incluye como modalidad con un capítulo específico en manuales generales, como los de Martínez Sierra (2012), Rica Peromingo (2016) o Talaván et al. (2016). 
A pesar de los avances en la didáctica de la AD, los estudios a nivel español todavía son escasos y es necesario llevar a cabo investigaciones que arrojen luz sobre las prácticas docentes actuales y sobre el perfil de los docentes. Este artículo pretende contribuir a ello.

\section{El proyecto ADLAB PRO}

ADLAB PRO es un proyecto financiado por la Unión Europea que tiene como uno de sus objetivos principales la creación de material didáctico para la formación de audiodescriptores profesionales. Para ello, pretende realizar en primer lugar un balance de la situación de los cursos existentes y de las competencias que incluyen, así como de las prácticas actuales en la formación de las competencias académicas y profesionales del sector. El proyecto lo lidera la Universidad de Trieste y en él participan como socios universidades (Universidad Autónoma de Barcelona, Universidad de Amberes y Universidad Adam Mickiewicz), empresas como Utopian Voices Ltd (https://www.utopianvoices.com/) y Soundfocus (http://soundfocus.nl/), asociaciones de usuarios, como el Royal National Institute of the Blind (https://www.rnib.org.uk/) y radiodifusores (la RTV eslovena), de seis países distintos (España, Italia, Reino Unido, Países Bajos, Polonia, Eslovenia). El proyecto se inició en 2016, tiene una duración de tres años, y consta de las fases siguientes:

(1) Evaluación de prácticas docentes actuales: pretende radiografiar los cursos en los que se enseña actualmente AD mediante una encuesta que recopila datos cuantitativos y entrevistas que permiten obtener datos cualitativos.

(2) Definición del perfil profesional del audiodescriptor: el objetivo de esta fase es identificar las competencias que debería tener un audiodescriptor, a partir de los resultados de una segunda encuesta y entrevistas con profesionales en activo y usuarios finales.

(3) Diseño del curso: partiendo de los resultados de las dos fases anteriores, se desarrollará el diseño de un curso para formar a audiodescriptores.

(4) Desarrollo de materiales didácticos: a partir del diseño establecido en la fase 3 , se crearán contenidos didácticos en varios formatos y lenguas, con el objetivo de que puedan ser usados en distintos contextos docentes. En paralelo a la creación de materiales, el proyecto llevará a cabo una evaluación de estos.

(5) Reconocimiento del curso y atribución de créditos: en esta fase se estudiará la cuantificación del curso en créditos y cómo se podría integrar y validar a nivel europeo, tanto en el ámbito universitario como en cursos dentro de la empresa. 
La investigación que presentamos en este artículo se inscribe dentro de la primera fase, liderada por la Universidad Adam Mickiewicz de Polonia. En ella se ha distribuido un cuestionario a nivel europeo para identificar de modo panorámico las prácticas docentes actuales. En el siguiente apartado describimos la metodología usada para recopilar los datos, que en este artículo se limitan a los obtenidos en España.

\section{Aspectos metodológicos}

Para recopilar datos sobre las prácticas docentes en AD, se desarrolló un cuestionario, coordinado por las investigadoras Agnieszka Chmiel e Iwona Mazur. El objetivo final era presentar una panorámica de las prácticas docentes y cursos de AD a nivel europeo, para poder entender las similitudes y diferencias entre países, así como las necesidades de cada uno de ellos. Asimismo, se llevó a cabo un estudio cualitativo de materiales usados en la práctica docente, cuyos resultados se pueden consultar en el informe final.

El equipo de Polonia desarrolló una primera versión del cuestionario que los distintos socios del equipo comentaron en distintas sesiones de trabajo virtuales y presenciales, hasta completar la versión final del cuestionario, que se validó en un estudio piloto.

El cuestionario incluía preguntas sobre la enseñanza de la AD tanto en entornos universitarios como en ámbitos profesionales y se distribuía del modo siguiente:

(1) Instrucciones y descripción de la estructura general.

(2) Perfil del docente.

(3) Sección sobre cursos universitarios: nivel, formato, modalidad presencial/virtual/semipresencial, duración, número medio de alumnos, destrezas, actividades y sistemas de evaluación empleados.

(4) Sección sobre cursos profesionales: formato, duración, número medio de alumnos, destrezas y actividades, certificación. En este apartado se incluían cursos en forma de talleres, cursos de formación profesional, cursos en empresas y formación individualizada.

(5) Preguntas generales: importancia de las competencias específicas y transversales, número de participantes en conjunto.

El cuestionario, redactado en inglés, se distribuyó en línea a través del servicio Instantly, en un formato accesible. Los destinatarios eran personas que impartían o habían impartido cursos de AD a cualquier nivel y en cualquier entorno. Teniendo en cuenta que algunos docentes quizás habían impartido múltiples 
cursos pero que a la vez quería reducirse el tiempo de respuesta del cuestionario a 25 minutos como máximo, se optó por limitar el número de repuestas a seis cursos por participante (un máximo de tres cursos universitarios y un máximo de tres cursos profesionales), impartidos todos ellos en los últimos tres años. La participación era anónima y solo al final podían aportar, si lo deseaban, información de contacto para seguir colaborando en el proyecto.

Para distribuir los cuestionarios, cada socio elaboró una lista de posibles contactos a los que distribuyó este material. En total se recogieron respuestas de 86 participantes de 6 países europeos, que aportaron información sobre un total de 192 cursos, de los cuales 93 eran cursos académicos de enseñanza superior y 99 profesionales (ADLAB PRO 2017: 4). En lo que compete a este artículo nos hemos centrado en el análisis de los encuestados en España. Un vaciado de los cursos de AD en España y de los académicos más activos en publicaciones científicas permitió identificar a 29 posibles docentes a los que se escribió por correo electrónico para solicitar su colaboración, así como contactos adicionales, llegando a un total de 38 posibles encuestados. Finalmente, fueron 27 encuestados los que participaron y se pudo recopilar información sobre un total de 66 cursos, de los cuales 46 eran cursos académicos y 20 profesionales.

\section{Análisis de resultados}

En primer lugar, presentaremos los datos pertenecientes al perfil de todos los encuestados y otros datos de carácter general. En segundo lugar, detallaremos los datos obtenidos sobre adquisición de competencias de los audiodescriptores. Finalmente, analizaremos en profundidad las respuestas obtenidas a partir de los cursos académicos y los cursos de carácter profesional.

\subsection{Preguntas generales del cuestionario}

Se preguntó a los encuestados por su perfil. Como era de esperar teniendo en cuenta la selección de estos, todos daban o habían dado clases de AD. Las respuestas (podían ser múltiples) extraídas de la pregunta "¿Quién es usted?" nos demuestran que el perfil de los encuestados se distribuye fundamentalmente entre investigadores, profesores de universidad y audiodescriptores.

Aislando los perfiles, observamos que un $74 \%$ son profesores de universidad, un $63 \%$ realizan labores de investigación y un $37 \%$ son audiodescriptores (Figura 1). Un 30\% trabaja o tiene algún tipo de puesto ejecutivo en una empresa que ofrece servicios de AD. En un porcentaje mucho menor, un 7\% son usuarios de servicios audiodescriptivos, y un 4\% locutores de AD. 


\section{¿Quién es usted?}

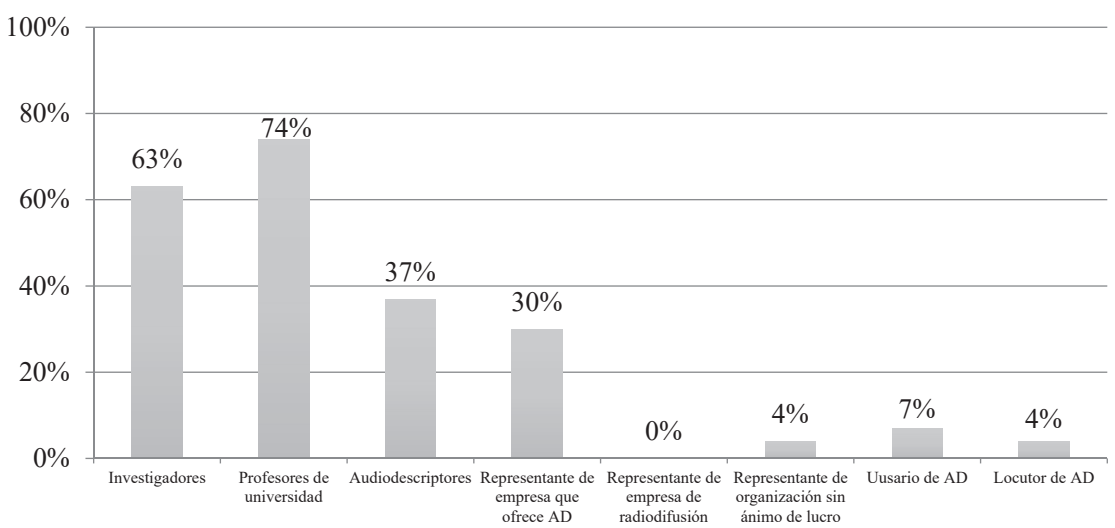

Figura 1. Perfil de los encuestados. Categorías aisladas (en \%)

Si analizamos los resultados centrándonos en las combinaciones más frecuentes entre las distintas categorías (Figura 2), la primera combinación es la de investigador y profesor de universidad, con un 59\% que se identifica con esos dos perfiles simultáneamente. Si nos preguntamos qué representación tiene la combinación del mundo académico y el profesional, los porcentajes son considerablemente menores: un $15 \%$ son profesores de universidad y audiodescriptores al mismo tiempo. En línea con esa combinación, un 11\% son investigadores y profesores universitarios, a la vez que audiodescriptores. Y si analizamos cuál es el porcentaje de encuestados que solamente trabajan como audiodescriptores de modo prioritario, encontramos que es un $15 \%$ de todos ellos.

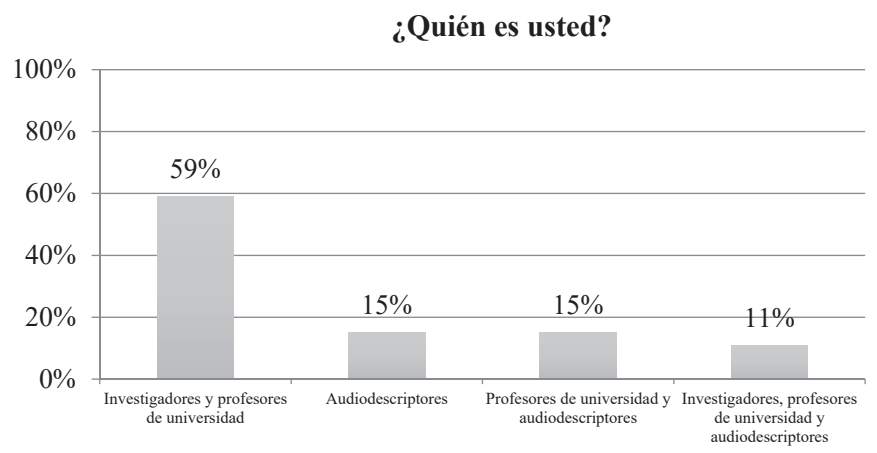

Figura 2. Perfil de los encuestados. Combinaciones más frecuentes de categorías (en \%) 
Los resultados descritos indican que el mundo académico de la AD y el profesional tienen sus propios caminos, aunque una mayor comunicación entre los mundos de la empresa y universidad, así como un mayor conocimiento mutuo, es recomendable en TAV (Cerezo Merchán 2013: 181). Los factores que influyen en una falta de mayor interconexión pueden ser varios. Entre ellos merece la pena destacar la dificultad que supone para profesionales que no son doctores impartir clases universitarias. Por una parte, si un profesional de estas características se plantea impartir clases a nivel de grado, con toda probabilidad tendrá que hacerlo con categoría de profesor asociado. Por otra parte, un número considerable de profesionales que podrían impartir docencia, pero que no son doctores, serán descartados por el sistema universitario español, que a nivel de máster oficial exige unos porcentajes mínimos de profesores con títulos de doctorado. Sin embargo, una mayor interconexión entre ambos mundos contribuiría en la enseñanza universitaria a la consecución de enfoques docentes que acerquen la realidad de la profesión a las aulas, un acercamiento certero de cara a la realidad profesional con la que se encontrarán los estudiantes, y a la obtención de posibles contactos con empresas cuando deban realizar prácticas laborales.

Una segunda pregunta aludía al tiempo que llevaban enseñando AD. El perfil español se reparte entre los que poseen una sobrada trayectoria y una más moderada: un 59\% oscila entre tres y diez años de experiencia, un 37\% ha enseñado AD durante menos de tres años y finalmente, un $4 \%$ son nuevos docentes, con una experiencia menor a un año.

La tercera pregunta era: " $¿ E s$ usted usuario de servicios de AD? En el caso de serlo, ¿utiliza servicios de AD a causa de alguna discapacidad visual?". Los datos obtenidos nos ofrecen el siguiente panorama: un 26\% sí utiliza servicios de AD mientras que un 74\% no lo hace. El 100\% de los encuestados que utiliza servicios audiodescriptivos no lo hace por causa de algún tipo de discapacidad visual. Es lógico deducir un interés personal, académico o profesional. El hecho de que los docentes sean usuarios habituales de los servicios de AD debería contribuir positivamente a que la experiencia de aprendizaje del estudiante sea más real. Por este motivo sería interesante conocer las razones por las cuales un porcentaje mayor no usa servicios de AD.

Según los datos obtenidos en la cuarta pregunta, referente a la frecuencia con la que cooperan los docentes con personas con discapacidades visuales (Figura 3), un 30\% de los encuestados coopera a menudo, un $7 \%$ lo hace siempre y un $22 \%$ a veces. En cambio, un $26 \%$ no coopera casi nunca y un $15 \%$ no lo hace nunca. 
Cuando enseña audiodescripción, ¿con qué frecuencia coopera con personas con algún tipo de discapacidad visual?

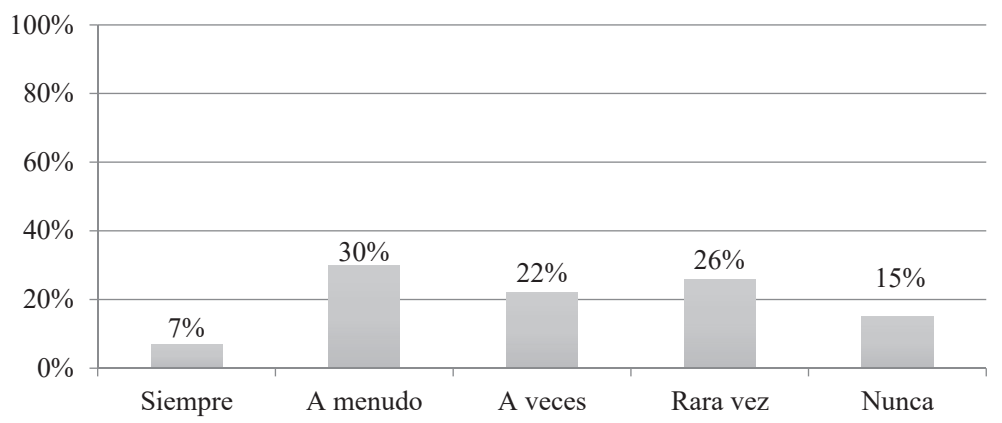

Figura 3. Perfil de los encuestados. Cooperación con personas con algún tipo de discapacidad visual (en \%)

A pesar de ser docentes españoles, queríamos ver en qué otros países enseñaban los encuestados. Mientras que un 77\% solo enseña en España, hay un 15\% que enseñan adicionalmente en algún otro país (una persona en Finlandia, otra en Bélgica, una tercera y una cuarta en Italia). El resto se distribuyen entre un 4\% que enseña en países de habla española, sin especificar cuáles, y otro 4\% que enseña en España, pero ha impartido sesiones de AD en Colombia.

En cuanto a la lengua o lenguas en las que realizan los guiones de AD durante sus cursos, las respuestas (múltiples si era necesario) son las esperadas: el 96\% de los encuestados lo hace en español y el 4\% lo hace en inglés. De los que usan la lengua española, el 36\% realiza guiones en español exclusivamente, mientras que el $26 \%$ trabaja con la realización de guiones de AD en español y en lengua catalana, el 15\% en español y en inglés, el $8 \%$ simultanea las lenguas española, inglesa y alemana, y el 15\% se reparte entre las combinaciones de español con respectivamente el inglés y el catalán, el francés, inglés, italiano y alemán, y otras lenguas en general, sin especificar.

La séptima pregunta se refería al tipo de AD que enseñaban los encuestados. Un 92\% (con posibilidad de respuestas múltiples) enseña AD de contenidos cinematográficos (Figura 4). Además de la AD para cine, un 44\% cubren la $\mathrm{AD}$ museística y un 30\% la teatral. La enseñanza de AD de ópera es señalada por un $15 \%$, al igual que la de otros eventos en directo (sin especificar cuáles) y un $26 \%$ imparte formación en AD de productos audiovisuales con fines didácticos. Por último, el patrimonio histórico, los documentales, las series, la zarzuela y la danza son tipos de productos que tienen cabida en la enseñanza de la $\mathrm{AD}$ con un $4 \%$ cada uno de ellos. 


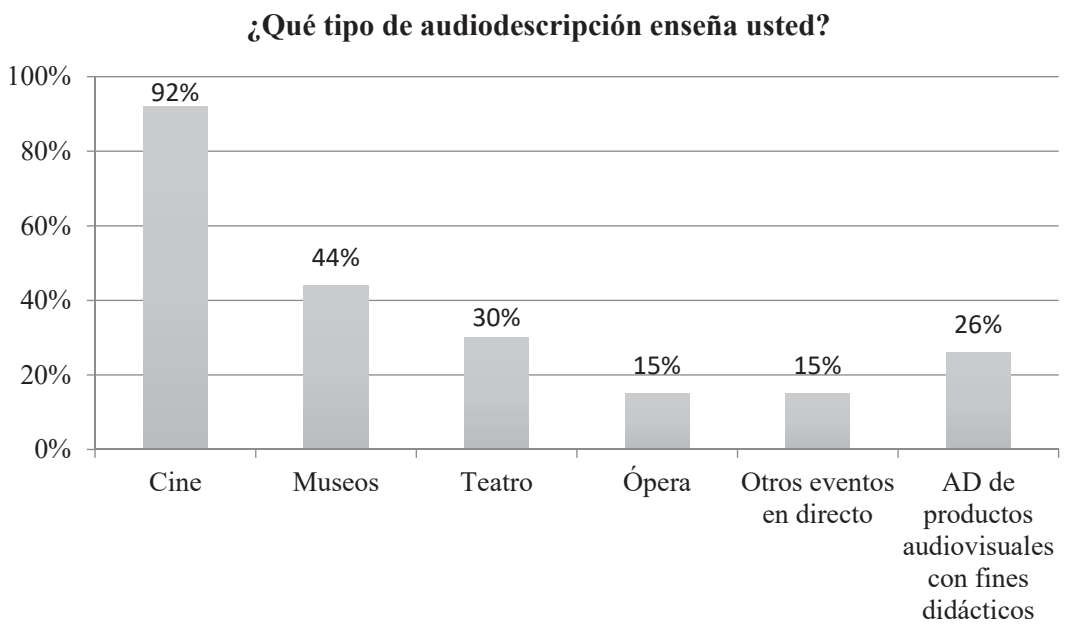

Figura 4. Productos audiovisuales enseñados en AD (en \%)

\subsection{Competencias}

En este apartado se presentaba una serie de competencias específicas y transversales que se estima que los futuros audiodescriptores deben adquirir en su formación. Se pedía a los encuestados puntuar ambas mediante una escala de Likert de 5 puntos ( 1 - no es importante; 2 - es poco importante; 3 - ni es importante ni no lo es; 4 - es importante; 5 - es muy importante). El cuestionario incluía al menos una pregunta referente a cada una de las cuatro categorías competenciales de Díaz Cintas (ver apartado 2) y tenía como objetivo ver la importancia que los audiodescriptores atribuyen a distintas competencias vinculadas a su perfil.

En cuanto a las competencias específicas, los encuestados (Tabla 1) otorgan la mayor importancia a la competencia de ser capaz de elegir la información más relevante para describir, muy estrechamente seguida por la de demostrar un uso perfecto del idioma materno y por la de poseer conocimientos sobre las necesidades de las personas ciegas y con discapacidad visual. A estas competencias le siguen otras situadas en la escala entre "importantes" y "muy importantes": la capacidad de elegir estrategias adecuadas de AD, la de poseer conocimientos tanto de carácter técnico como de los productos audiovisuales y la semiótica de la imagen. Los encuestados dan una importancia media (en el baremo "ni es importante ni no lo es") al resto de las competencias específicas: las destrezas vocales, ser capaz de reflejar el lenguaje cinematográfico al audiodescribir y tener conocimientos sobre las tecnologías de la información. 


\begin{tabular}{|l|c|}
\hline \multicolumn{1}{|c|}{ Competencias específicas } & $\begin{array}{c}\text { Puntuación media } \\
\text { (sobre 5) }\end{array}$ \\
\hline Ser capaz de elegir la información más relevante para describir & 4,88 \\
\hline Perfecto uso del idioma materno & 4,85 \\
\hline $\begin{array}{l}\text { Conocimientos sobre las necesidades de las personas con } \\
\text { discapacidad visual }\end{array}$ & 4,70 \\
\hline $\begin{array}{l}\text { Ser capaz de elegir estrategias de AD adecuadas (por ej. decidir } \\
\text { cuando nombrar a un personaje) }\end{array}$ & 4,48 \\
\hline $\begin{array}{l}\text { Aspectos técnicos (montaje, sincronización, condensación } \\
\text { textual) }\end{array}$ & 4,11 \\
\hline $\begin{array}{l}\text { Conocimientos sobre cinematografía, teatro, las artes y/o la } \\
\text { semiótica de la imagen }\end{array}$ & 4 \\
\hline Destrezas vocales & 3,59 \\
\hline $\begin{array}{l}\text { Reflejar el lenguaje cinematográfico (montaje y movimientos de } \\
\text { cámara) }\end{array}$ & 3,40 \\
\hline $\begin{array}{l}\text { Destrezas relacionadas con las tecnologías de la información } \\
\text { (saber usar programas informáticos, etc.) }\end{array}$ & 3,22 \\
\hline
\end{tabular}

Tabla 1. Competencias específicas en orden de importancia

De las cuatro competencias transversales incluidas, los encuestados en España (Tabla 2) consideraron todas entre "importantes" y "muy importantes", pero otorgaron la mayor importancia a ser capaz de organizar eficientemente el trabajo y de gestionar el tiempo. En segundo lugar, observamos la relevancia que tienen los aspectos éticos, lo que parece ir en línea con la sensibilidad inherente a temas relacionados con la accesibilidad en los medios. A poca distancia se sitúa la competencia de desarrollo personal. Sin contar con más datos, esto puede responder a que los encuestados aprecian la relevancia de que los futuros audiodescriptores estén en constante crecimiento personal, lo que está indirectamente relacionado con el desarrollo también continuo de sus demás competencias. Por último, los encuestados eligen el hecho de saber trabajar en equipo. Aunque se trata de una competencia transversal y no específica de la $\mathrm{AD}$, puede deducirse que los encuestados relacionen la $\mathrm{AD}$ como un trabajo que se desarrolla en solitario en gran parte. 


\begin{tabular}{|l|c|}
\hline \multicolumn{1}{|c|}{ Competencias transversales } & $\begin{array}{c}\text { Puntuación media } \\
\text { (sobre 5) }\end{array}$ \\
\hline Organización eficiente del trabajo y gestión del tiempo & 4,62 \\
\hline Aspectos éticos & 4,40 \\
\hline Desarrollo personal & 4,22 \\
\hline Trabajo en equipo & 4,14 \\
\hline
\end{tabular}

Tabla 2. Competencias transversales en orden de importancia

\subsection{Cursos de $A D$}

Los dos siguientes apartados del cuestionario tenían como objetivo obtener información sobre las características de cursos académicos universitarios y de los cursos profesionales impartidos por los docentes. En lo referente a los primeros, se aspiraba a saber su nivel (grado, máster o posgrado), y el formato del curso, es decir, si el curso de AD era un curso en sí mismo o formaba parte de otro. Además, se preguntó sobre la modalidad de los cursos (presencial, a distancia o semipresencial), sobre su duración, sobre el tamaño del grupo, sobre las aptitudes y habilidades que se trabajaban, así como sobre las actividades en las que se centraban. Finalmente, se recopiló información sobre el sistema de evaluación seguido. En lo referente a los segundos, la encuesta se centró en los cursos de carácter profesional. Las preguntas fueron las mismas, con las siguientes excepciones: no se preguntó por la modalidad de enseñanza de los cursos ni tampoco por su nivel. Al igual que con los cursos de carácter académico, sí se preguntó por el formato de los cursos, pero en este caso en referencia a si se componía de talleres, o si se trataba de cursos de capacitación profesional, de formación interna o de formación individualizada. Tampoco se preguntó sobre sistemas de evaluación, pero en cambio sí se pretendía saber si la realización del curso terminaba con la expedición de algún tipo de certificado o diploma.

A continuación, detallaremos los resultados obtenidos en cada apartado de esta sección del cuestionario, comenzando con los cursos académicos, siguiendo con los profesionales y por último estableciendo una comparación entre ambos.

\subsubsection{Cursos académicos universitarios}

El cuestionario se interesaba por saber qué porcentaje de los encuestados imparte cursos académicos universitarios y qué porcentaje de carácter profesional. Un 
81\% imparte cursos académicos universitarios, el 48\% imparte exclusivamente cursos académicos, y el 33\% compagina la impartición de cursos académicos con otros profesionales. En total, recopilamos información de un total de 46 cursos académicos impartidos en universidades. Se estima que un mínimo de 950 estudiantes realizó estos cursos en los últimos tres años. Es decir, el 54\% de los encuestados afirma que más de 60 personas participaron en los cursos en los últimos tres años, mientras que un 23\% asegura que lo hicieron entre 21 y 40 personas, un $14 \%$ entre 41 y 60 personas y por último el $9 \%$ responde que sus cursos se compusieron de menos de 20 personas en los últimos tres años.

En cuanto al nivel al que se imparten (Figura 5), distinguimos un perfil repartido entre la impartición de AD en grado (30\%), máster (48\%) y posgrado (22\%). El hecho de que los cursos de AD estén más presentes en estudios de máster puede responder al hecho de que estos presentan un nivel de especialización suficiente para poder dedicar apartados propios a la $\mathrm{AD}$, en contraste con cursos de grado que requieren la inclusión de múltiples contenidos de diferentes áreas y conllevan la dificultad de dar cabida a áreas más especializadas. A la pregunta de si cada curso de AD constituía en sí mismo un curso o era parte integrante de uno, un $41 \%$ son exclusivamente de $\mathrm{AD}$, mientras que un $57 \%$ se integran en su mayoría en cursos sobre TAV, bien a nivel de grado o de máster. Del 2\% restante obtenemos la información de que se trata de cursos optativos. En cuanto a la modalidad de enseñanza (Figura 6), el panorama se compone de cursos presenciales en un $65 \%$, seguidos de un $22 \%$ de cursos virtuales, y de un 13\% de semipresenciales.

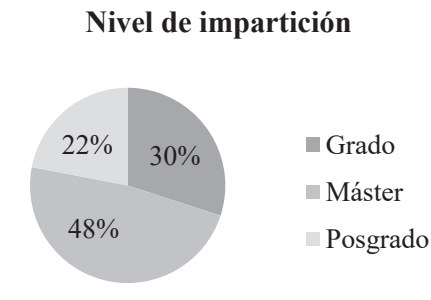

Figura 5. Nivel de impartición de los cursos académicos

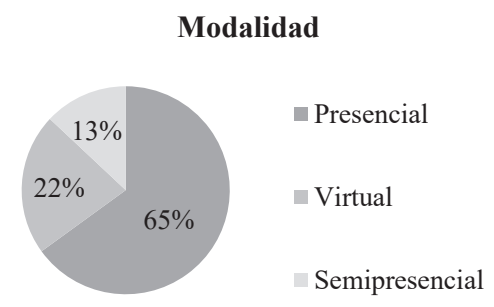

Figura 6. Modalidad de mpartición de los cursos académicos

En referencia a los datos recogidos sobre la duración de los cursos de forma aislada, los resultados nos muestran el siguiente panorama (Figura 7): un 43\% tienen una duración menor a 10 horas, la de un 20\% es de entre 10 y 20 horas, mientras que la duración de un 11\% de los cursos oscila entre 21 y 30 horas y finalmente un $26 \%$ de los cursos se componen de más de 30 horas. Si comparamos la duración respecto de la modalidad en la que han sido impartidos, la 
tendencia más destacada es la de cursos que constan de menos de 10 horas y que son impartidos en modalidad presencial ( $31 \%$ de todos los cursos académicos). En porcentajes menores se sitúan los cursos de entre 10 y 20 horas impartidos presencialmente (18\%) y los cursos con una duración mayor a 30 horas impartidos igualmente en modalidad presencial (13\%). A continuación encontramos los cursos de una duración menor a 10 horas impartidos virtualmente (11\%). El resto de las combinaciones no permiten destacar tendencias, más allá de la menor representación de cursos impartidos semipresencialmente o de forma virtual. Por tanto, la mayor relación de la duración de los cursos en relación con su modalidad está en línea con la mayor presencia de cursos presenciales en este cuestionario.

En relación con el tamaño de los grupos, un $11 \%$ de los cursos académicos tiene menos de 10 estudiantes por grupo, un $52 \%$ entre 10 y 20 , y por último un $37 \%$ de los cursos tienen más de 20 estudiantes en el aula. Esta última cifra es considerablemente alta como para interesarnos más detalladamente en futuros trabajos sobre cuántos alumnos se componen esos grupos formados por más de 20 estudiantes.

\section{Duración}

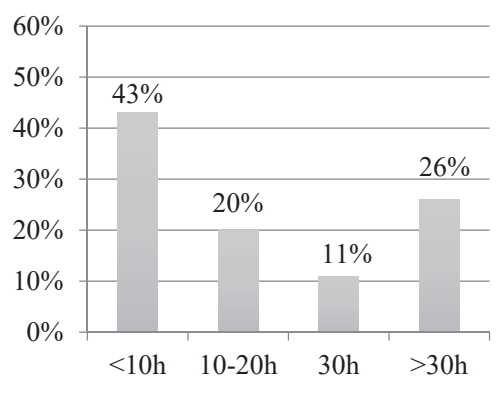

Figura 7. Duración de los cursos académicos

\section{Tamaño}

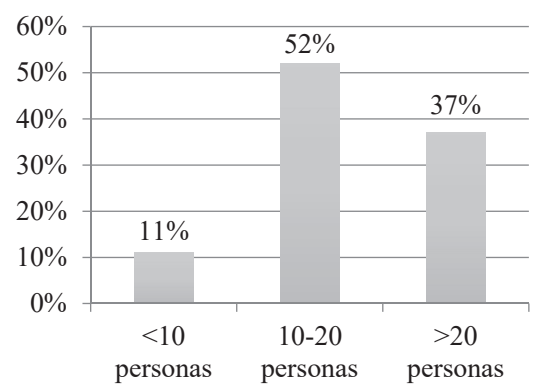

Figura 8. Tamaño de los cursos académicos

Un apartado específico del cuestionario preguntaba por las destrezas que se enseñan, con opción de respuestas múltiples. Hay unanimidad en la creación de guiones de AD con un $87 \%$ de los cursos que las incluyen (Tabla 3), así como un $85 \%$ que reparan en la importancia del conocimiento y concienciación de las necesidades de las personas ciegas y con baja visión. Proporcionalmente y muy por debajo, se sitúa con un $24 \%$ de los cursos el conocimiento de programas informáticos específicos de la $\mathrm{AD}$, y con un $22 \%$ el tratamiento de las grabaciones de AD. Finalmente, los encuestados reflejan que en un $17 \%$ de sus cursos respectivamente también trabajan la locución de AD y la traducción de guiones AD de otras lenguas a la materna. 


\begin{tabular}{|l|c|}
\hline \multicolumn{1}{|c|}{ Destrezas que se enseñan los cursos académicos } & Porcentaje \\
\hline Creación de guiones de AD & $87 \%$ \\
\hline $\begin{array}{l}\text { Concienciación sobre las necesidades de las personas con } \\
\text { discapacidad visual }\end{array}$ & $85 \%$ \\
\hline Uso de programas informáticos aplicados a AD & $24 \%$ \\
\hline Grabación de AD & $22 \%$ \\
\hline Locución de AD & $17 \%$ \\
\hline Traducción de AD a la lengua materna de los estudiantes & $17 \%$ \\
\hline
\end{tabular}

Tabla 3. Destrezas en \% de uso de los cursos profesionales

En cuanto al tipo de actividades, las respuestas, que podían ser múltiples, indican que los cursos incluyen: el análisis de AD existentes (96\%), la realización de ejercicios prácticos (93\%), la discusión de directrices de AD (87\%), así como la presentación de teoría relacionada con la AD (85\%), por ejemplo, de artículos de investigación. Esta tipología de actividades parece estar en sintonía con metodologías docentes actuales en el aula de traducción, fruto de una reflexión profunda dentro del ámbito de los estudios de traducción (Kiraly 2003/2014; González Davies 2004; Huertas Barros 2013).

En cuanto a los sistemas de evaluación de los cursos, un 91\% de los cursos tienen en cuenta la participación para la evaluación. Un 74\% requiere de los alumnos la realización de tareas dirigidas y un $72 \%$ la creación de un guion de AD. A distancia considerable están el 15\% que basan la evaluación en exámenes y el 9\%, en el que los alumnos deberán escribir algún tipo de trabajo relacionado con el área de la $\mathrm{AD}$.

Evaluación de los cursos

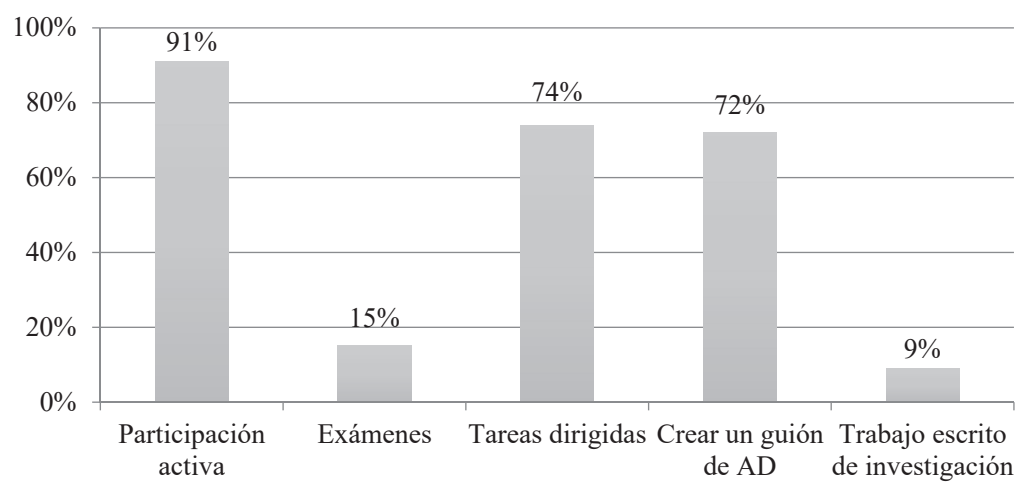

Figura 9. Sistemas de evaluación de los cursos (en \%) 


\subsubsection{Cursos de carácter profesional}

En cuanto a los cursos de carácter profesional, estos se vieron representados por un 52\% (14 de 27 personas respondieron a ese perfil). A su vez el 19\% imparte cursos de carácter profesional solamente. En total se recogió información sobre 20 cursos de este tipo. Por otra parte, se puede estimar que en ellos participaron un mínimo de 331 estudiantes en los últimos tres años. O explicado de otra forma, el $43 \%$ de los encuestados afirman que participaron menos de 20 estudiantes, el $21 \%$ afirman que en sus cursos participaron más de 60 , otro $21 \%$ que participaron entre 21 y 40 y finalmente el $14 \%$ responden que entre 41 y 60 estudiantes participaron en sus cursos en los últimos tres años.

Observamos que el $60 \%$ de los cursos profesionales tenían el formato de talleres, frente a un 15\% que representaban los cursos orientados a formación profesional y otro $15 \%$ perteneciente a cursos dirigidos a empresas. Finalmente, el $10 \%$ se dirigen a formación individualizada. El hecho de que más de la mitad de los cursos sean talleres refleja que son eminentemente prácticos, lo que lógicamente debería contribuir a acercar la realidad profesional al futuro audiodescriptor. Si atendemos a la duración de los cursos (Figura 10), observamos que la duración del $40 \%$ de los cursos es menor a 10 horas. A su vez, un $25 \%$ tienen una duración de entre 10 y 20 horas y la de un $15 \%$ es de entre 21 y 30 horas. Por último, también existen cursos de más de 30 horas, en concreto el $20 \%$.

En cuanto al tamaño de los cursos profesionales (Figura 11), el panorama se reparte así: el 40\% se compone de menos de 10 personas, frente a otro $40 \%$ de los cursos cuyo tamaño es de entre 10 y 20 personas y un $20 \%$ con grupos más numerosos de 20 personas o más.

Duración

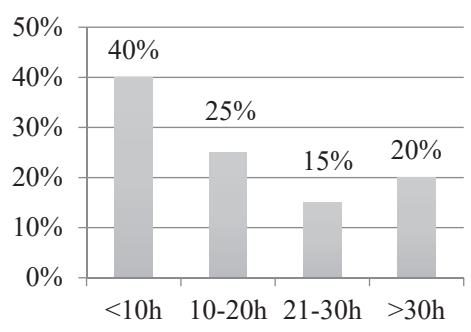

Figura 10. Duración de los cursos profesionales
Tamaño

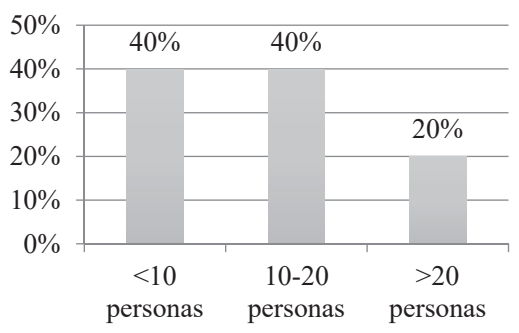

Figura 11. Tamaño de los cursos profesionales

Sobre las destrezas (Tabla 4), recogidas en un apartado con posibilidad de múltiples respuestas, un $85 \%$ de los cursos incluyen la creación de guiones de 
$\mathrm{AD}$, seguidos de un $75 \%$ que enseña a concienciar sobre las necesidades de las personas con discapacidad visual. A bastante distancia se sitúan el $35 \%$, que trabajan con el uso de programas informáticos aplicados a $\mathrm{AD}$, y el $25 \%$ que enseñan la habilidad de grabar audiodescripciones. Finalmente, la locución de AD la incluye un $20 \%$ de los cursos y la traducción de AD a la lengua materna de los estudiantes un $15 \%$.

\begin{tabular}{|l|c|}
\hline \multicolumn{1}{|c|}{ Destrezas que se enseñan en los cursos profesionales } & Porcentaje \\
\hline Creación de guiones de AD & $85 \%$ \\
\hline $\begin{array}{l}\text { Concienciación sobre las necesidades de las personas con } \\
\text { discapacidad visual }\end{array}$ & $75 \%$ \\
\hline Uso de programas informáticos aplicados a AD & $35 \%$ \\
\hline Grabación de AD & $25 \%$ \\
\hline Locución de AD & $20 \%$ \\
\hline Traducción de AD a la lengua materna de los estudiantes & $15 \%$ \\
\hline
\end{tabular}

Tabla 4. Destrezas en porcentajes de uso de los cursos profesionales

Según los datos obtenidos, la mayoría de los cursos profesionales incluían sobre todo actividades prácticas (80\%) y actividades relacionadas con el análisis de AD reales (80\%). A su vez, un 55\% incorporan la presentación de aspectos teóricos de AD y también un 55\% actividades vinculadas a la discusión de directrices de la AD.

Para obtener una radiografía general sobre los cursos profesionales, resultaba útil conocer si estos otorgaban a su finalización algún tipo de acreditación. El 65\% sí lo hace, mientras que un 35\% no. Estudios más detallados podrían respondernos el porqué en ambos casos, así como proporcionarnos más información sobre el tipo de acreditaciones, diplomas o certificados conseguidos y las instituciones que los expiden.

\subsubsection{Comparación entre los cursos académicos y los profesionales}

Si bien la población obtenida difiere ( 46 cursos académicos, 20 cursos profesionales), podemos establecer una comparación entre ambos tipos de cursos y extraer tendencias. En cuanto a la duración de los cursos (Figura 12), un 43\% de los académicos y un $40 \%$ de los profesionales tienen una duración menor a 10 horas. El resto de las categorías varían ligeramente: la segunda más frecuente para los cursos académicos es la de una duración superior a 30 horas (26\%), frente a la de los cursos profesionales, que sitúan en segundo lugar cursos ligeramente más cortos, de entre 10 y 20 horas (25\%). 


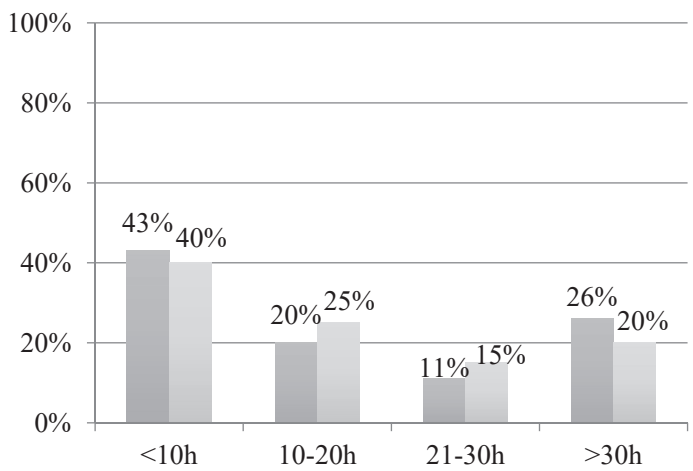

\section{Duración}

- Académicos

Profesionales

Figura 12. Duración de los cursos académicos y de los profesionales

En referencia al número de estudiantes (Figura 13), los cursos académicos se componen de grupos más numerosos por curso, con un $52 \%$ que constan de entre 10 y 20 personas, un $37 \%$ con más de 20 y por último un $11 \%$ con grupos de menos de 10. En el caso de los cursos profesionales, la situación varía, ya que un $40 \%$ de los cursos respectivamente se compone de menos de 10 personas y de entre 10 y 20. En cambio, la categoría de grupos con más de 20 se queda en el último lugar, representada en un $20 \%$.

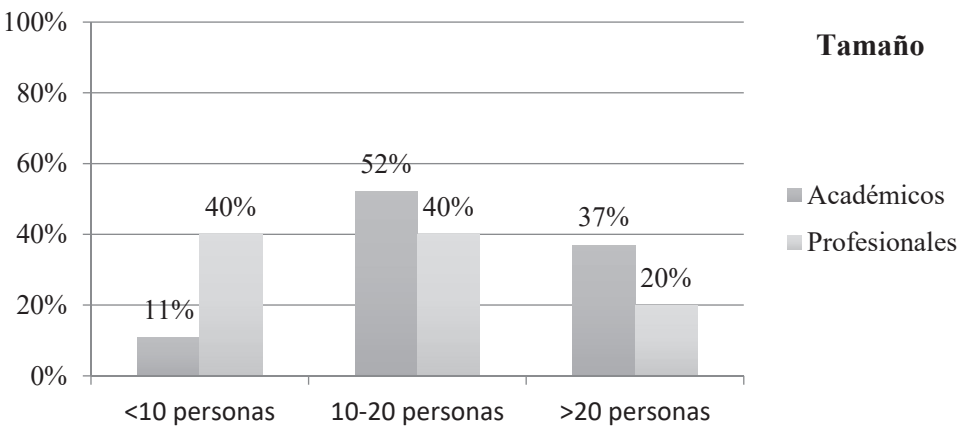

Figura 13. Tamaño de los cursos académicos y de los profesionales

Por otra parte, quisimos comparar la duración y el tamaño de los dos tipos de cursos. Sobre los cursos académicos, en primer lugar, se sitúan los de menor duración ( $>10$ horas) que están compuestos, bien de entre 10 y 20 estudiantes ( $20 \%$ de todos los cursos, teniendo en cuenta su duración y tamaño), o de más de 20 estudiantes (17\%). En segundo lugar, los cursos de mayor duración ( $>30$ horas) que constan de entre 10 y 20 estudiantes (17\% del total de los cursos 
académicos). Por debajo de las anteriores cifras se sitúan los cursos con una duración de entre 10 y 20 horas que se componen de entre 10 y 20 estudiantes $(11 \%)$. El resto de las posibles combinaciones resultan en una variación estadística amplia de entre el $2 \%$ y el $7 \%$, sin poder obtener más tendencias, en cuanto a la relación entre duración y tamaño de este tipo de cursos. Es decir, hasta donde pueden llegar nuestros datos, tanto los cursos largos como los cursos cortos incluyen a la horquilla media de tamaño del grupo. Lo anterior puede aportar información útil de cara a la planificación de la preparación de los contenidos a impartir, así como sobre qué nivel de profundización pueden prever los docentes, teniendo en cuenta la duración frente al tamaño.

En referencia a los cursos profesionales, con la información obtenida en este caso no es posible extraer tendencias sobre si los cursos de mayor duración se componen de grupos de mayor o menor tamaño. Por el contrario, la conclusión al respecto es que la tendencia resulta ser la existencia equilibrada de todas las posibles combinaciones.

Si nos referimos a las destrezas que se incluyen en ambos tipos de cursos (Figura 14), encontramos una gran similitud en la mayoría de las categorías, con alguna excepción a resaltar, como es el porcentaje mayor dedicado en los cursos profesionales al conocimiento de los programas informáticos aplicados a la $\mathrm{AD}$, respecto de los académicos (35\% frente a $24 \%$ respectivamente). Es lógico que los cursos profesionales tengan una necesidad más inmediata del uso de ciertos programas informáticos en particular, y los resultados parecen estar en línea con esta deducción.

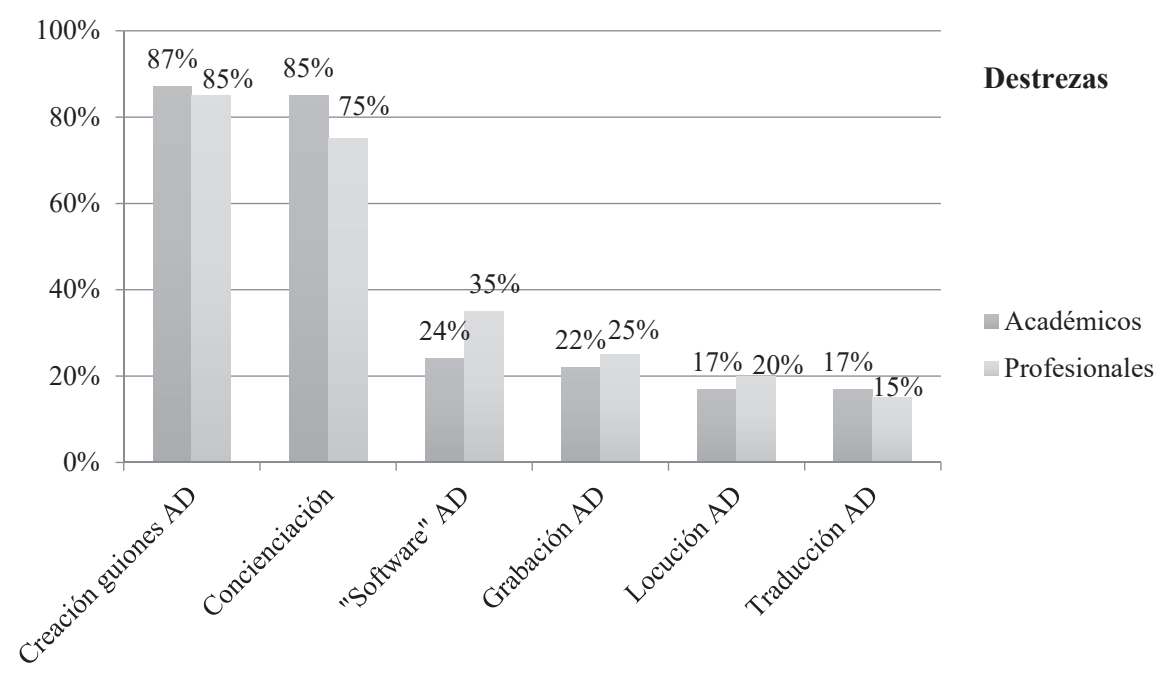

Figura 14. Destrezas de los cursos académicos y de los profesionales 
Asimismo, comparamos la duración de los cursos con las destrezas que se priorizan. El dato más visible es que la mayoría de los cursos, independientemente de su duración, incluyen entre las destrezas necesarias la creación de guiones de $\mathrm{AD}$, así como la concienciación sobre las necesidades de las personas ciegas o con algún tipo de discapacidad visual. Por una parte, en cuanto a los cursos académicos, concluimos que, de entre aquellos con una duración menor a 10 horas, el $85 \%$ se enfocan en concienciar sobre las necesidades mencionadas y el $80 \%$ en la creación de guiones de AD. Estas cifras son muy superiores a las obtenidas en el resto de las categorías en este tipo de cursos con esta duración en concreto: el $0 \%$ de ellos se enfocan en la locución de AD, el 10\% en la traducción de guiones de $\mathrm{AD}$ existentes y otro 10\% en la grabación de audiodescripciones. Esto puede explicarse porque en el contexto español es habitual crear audiodescripciones y no traducir audiodescripciones existentes (lo que vendría a ser una traducción interlingüística de una lengua B al español que sirve de base para llevar a cabo una traducción intersemiótica del contenido visual en palabras). Del mismo modo, en el contexto español es habitual que en la mayoría de productos grabados sea un actor de doblaje, y no el propio audiodescriptor, quien realice la locución de la $\mathrm{AD}$ en un estudio de grabación.

Los datos obtenidos en los cursos de diferente duración están en la misma línea. Sobre los de duración de entre 10 y 20 horas, el 90\% se enfocan en la creación de guiones de AD y en concienciar, respectivamente. El 93\% de los cursos de una duración mayor a 30 horas en la creación de guiones de AD y el $71 \%$ en la concienciación. Por último, en lo referente a los cursos académicos de 21 a 30 horas, el porcentaje resulta ser menor: 60\% consideran necesarias las destrezas de creación de guiones y la de concienciar, respectivamente. Por otra parte, los cursos profesionales presentan tendencias similares a los académicos, entre las que destacamos algunas. El 100\% de los cursos con duraciones de menos de 10 horas, de 21 a 30 horas y de más de 30 horas se enfocan tanto en la creación de guiones de AD como en la concienciación. Otro dato llamativo es que la duración de los cursos puede influir en la utilización de programas informáticos: en los académicos, un 57\% con una duración mayor a 30 horas los usan, frente al $40 \%$ de los cursos de entre 21 y 30 horas, el $12 \%$ de entre 10 y 20 horas y el 10\% de los cursos con menos de 10 horas. Si hablamos de los cursos profesionales, el 100\% de duración mayor a 30 horas se enfocan en la destreza de uso de programas informáticos. En este sentido, es interesante destacar que, a pesar de que existen programas de $\mathrm{AD}$ específicos, no es extraño que algunos profesionales trabajen con un procesador de textos y un programa de reproducción de vídeo o incluso con programas de subtitulación. El hecho de incluir programas específicos en la formación puede venir condicionado 
por la disponibilidad y coste asociado a los mismos, al conocimiento previo por parte de los formadores o de los estudiantes de programas parecidos (por ejemplo, de subtitulación) o a la relativa importancia que se otorgue a los programas informáticos.

La última comparación es la del tipo de actividades incluidas en ambos tipos de cursos (Figura 15). Destacamos el enfoque mayor en los aspectos prácticos y funcionales, frente a los conceptuales, de los cursos profesionales. El 80\% incluyen ejercicios prácticos, pero las demás categorías se sitúan por debajo, bien sea la de análisis de AD reales (60\%), la de discusión de directrices de $\mathrm{AD}(55 \%)$ o la de teoría relacionada con la $\mathrm{AD}$ (55\%). Es lógico deducir que para los cursos académicos es relevante incluir ejercicios prácticos, en porcentajes muy altos, pero que además, hagan lo mismo con tipos de actividades de discusión y teoría. Del mismo modo, es entendible que los entornos profesionales se centren en mayor medida en lo práctico, frente a lo teórico.

\section{Actividades}

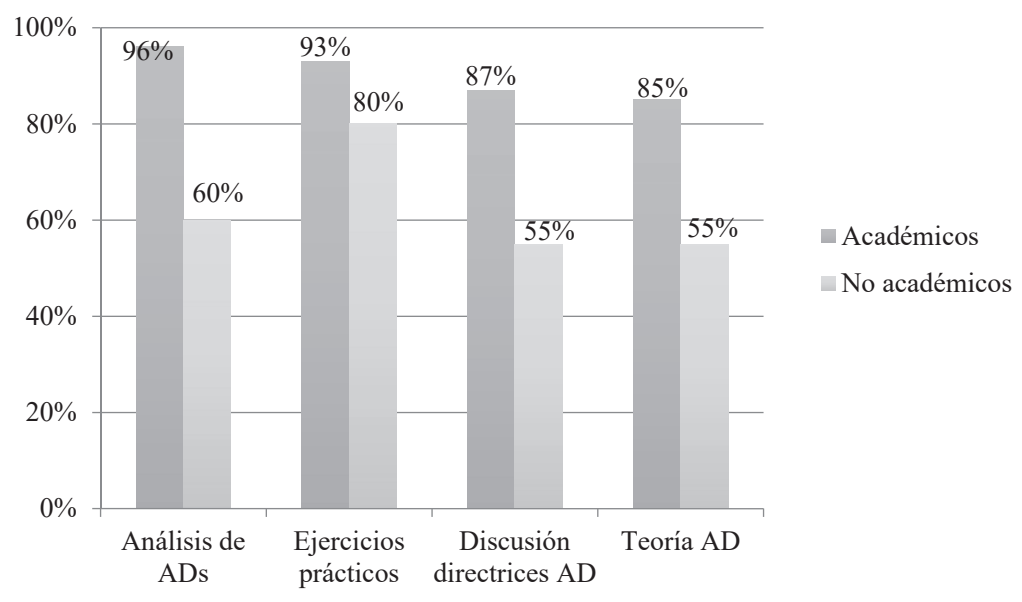

Figura 15. Tipos de actividades de los cursos académicos y de los profesionales

\section{Conclusiones}

Este artículo tenía como objetivo observar panorámicamente el perfil de los docentes que enseñan $\mathrm{AD}$ en España, identificar las características de los cursos que imparten y las destrezas que se consideran más importantes en la formación de audiodescriptores.

En cuanto al perfil de los docentes, más de la mitad son profesores a la vez que investigadores, poco más de una décima parte son profesores y 
audiodescriptores simultáneamente, y aproximadamente solo una décima parte son profesores, investigadores y audiodescriptores. Esto nos lleva a concluir que es deseable que las universidades y el mundo profesional estén interrelacionados en la medida de lo posible. El Espacio Europeo de Educación Superior (EEES), y la adaptación de los sistemas educativos en Europa a este, ha redefinido la relación entre enseñanza y aprendizaje y por tanto entre los docentes y los estudiantes. Una de las recomendaciones es que se implementen metodologías alternativas que innoven, y que estén basadas en acciones conjuntas que posibiliten descubrir, construir y transformar conocimientos, conjuntamente entre los docentes y los estudiantes (Huertas Barros 2013: 29). Estas acciones y muchas otras se definen en los múltiples enfoques de enseñanza y aprendizaje de traductores que existen. También con el EEES estos enfoques han experimentado un gran cambio: el paso de las teorías tradicionales de la enseñanza, transmisionistas y reduccionistas, a otras más integradoras. Si bien tanto el perfil académico como el profesional está representado en el cuestionario, es beneficioso que se trabaje en aún más incremento del perfil llamado "practisearcher", que aúna los conocimientos académicos con los de su práctica profesional real. Sin embargo, la realidad del sistema universitario español dicta unos mínimos porcentajes de profesores doctores en sus filas en determinados programas académicos, lo que puede dificultar el acceso a la docencia de profesionales que no sean doctores.

En cuanto a su experiencia docente de $\mathrm{AD}$, observamos que más de la mitad de los encuestados poseen una trayectoria de entre 3 y 10 años, y menos de la mitad de menos de 3 años. Nos planteamos algunas preguntas para estudios futuros, como es saber qué porcentaje de los encuestados disfrutan de una continuidad en la enseñanza de sus cursos. Esto nos ayudaría a recopilar información sobre posibles procesos de evolución metodológica de los docentes.

Vemos también que tres cuartas partes de los encuestados no usan AD, mientras que una cuarta parte sí. Casi un tercio coopera frecuentemente con personas con discapacidad visual mientras que más de un cuarto no coopera casi nunca. Se pueden apuntar algunas posibles causas que explicarían por qué el porcentaje de encuestados que usan $\mathrm{AD}$, así como el de los que coopera con personas con discapacidad, no es mayor. Una de ellas podría ser la falta de tiempo material a la que podrían tener que enfrentarse los encuestados, al realizar sus tareas académicas y profesionales, para aquellos que combinan ambas. Si añadimos a plazos ya limitados la posible dificultad de acceder a colaboraciones con personas ciegas o con discapacidad visual, el reto puede convertirse en demasiado ambicioso. Otro dato que merece la pena destacar es el hecho de que los encuestados, tanto los que imparten cursos académicos 
como profesionales, no son personas con discapacidad visual. Es decir, no necesitan consumir servicios de AD en su vida diaria, aunque algunos de ellos sí lo hagan por interés personal, académico o profesional. En contraste con lo anterior, el caso de docentes de subtitulación (excluyendo la subtitulación para sordos), o de doblaje, por ejemplo, puede diferir en tanto en cuanto a la exposición y frecuencia de uso de productos subtitulados o doblados en su vida diaria. En cualquier caso, el hecho de que los formadores de AD utilice servicios audiodescriptivos y cooperen con los usuarios está en línea con los postulados del enfoque didáctico socioconstructivista para traductores, que propone un proceso sociopersonal e interactivo en el aula (Kiraly 2003: 29). Por tanto, futuros estudios podrían ahondar en los motivos por los cuales el porcentaje de encuestados que usa la $\mathrm{AD}$ y colabora con usuarios no es mayor.

En cuanto a las competencias específicas más importantes, elegir la información relevante fue la primera, seguida del dominio de la lengua materna y del conocimiento de las necesidades de los usuarios. En cambio, las menos importantes fueron el uso del lenguaje fílmico y la utilización de programas informáticos aplicados a AD. En cuanto al grado de utilización de programas, la duración de los cursos puede ser un factor a tener en cuenta. En cuanto a las transversales, las más importantes fueron la organización eficiente del trabajo y del tiempo, los aspectos éticos, la capacidad de desarrollo personal y el trabajo en equipo. Es relevante que ninguna de las competencias propuestas fuera considerada como poco importante o de ninguna importancia. Los encuestados otorgaron mayor importancia a las competencias lingüísticas y temáticas que a las técnicas.

Sobre el nivel al que se imparten los cursos, pudimos observar en el ámbito universitario un predominio de los cursos de posgrado o máster que prioritariamente se enseñan presencialmente. En cuanto a los cursos profesionales, más de la mitad tenían formato de taller y el resto estaban orientados a una formación profesional y dirigido a empresas. Sobre duración y tamaño, los profesionales son ligeramente más cortos que los académicos y los primeros constan de grupos ligeramente más reducidos. Resaltamos que las aulas compuestas por grupos grandes pueden tender a dificultar enfoques de aprendizaje centrados en el alumno, e indirectamente favorecer enfoques pedagógicos más tradicionales (Kiraly 2003: 27). En este sentido, hay cierto consenso en que el aprendizaje requiere la unión de esfuerzos intelectuales por parte de los estudiantes y de los docentes en conjunto (Leigh Smith \& MacGregor 1992) en grupos de trabajo reducidos (Johnson \& Johnson 2017; Johnson et al. 1994).

En lo referente a las destrezas enseñadas, son muy similares en ambos tipos de cursos. Los profesionales otorgan una importancia mayor al uso de 
programas informáticos aplicados a $\mathrm{AD}$, en comparación con los cursos académicos. Por su parte, en lo referente a los tipos de actividades, ambos incluyen diferentes y variadas, con una diferencia considerable en la menor importancia que otorgan los cursos profesionales a tipos de actividades teóricas y conceptuales.

Finalmente, sobre la evaluación de los cursos académicos, podemos deducir que es en gran parte formativa. La evaluación sumativa está representada, pero en una medida considerablemente menor. Esta es la tendencia que siguen los enfoques socioconstructivistas, por ejemplo, de carácter colaborativo y cooperativo, en el que se pueden evaluar dos aspectos: por una parte, cuál es el resultado final en relación con los contenidos que se han impartido. Por otra parte, la participación activa del estudiante en un proceso grupal (Huertas Barros 2013: 141). Estudios más detallados nos permitirían adentrarnos, además de en aspectos más concretos de evaluación formativa y sumativa, en el tema de la autoevaluación, que de momento no se ha contemplado en este cuestionario.

Todos los datos obtenidos han contribuido a presentar una primera fotografía del perfil de los docentes en el ámbito de la AD en España y las características de los cursos que imparten. Al mismo tiempo que ha aportado información novedosa en un ámbito en el que hay muy poca investigación, se ha hecho evidente la necesidad de llevar a cabo una radiografía más detallada. Este será el objetivo de fases posteriores de esta investigación, que pueden centrarse en analizar con más detalle los diseños curriculares existentes en AD en España y su evolución, las competencias, destrezas y resultados de aprendizaje, las actividades docentes y las actividades de evaluación.

\section{Referencias bibliográficas}

ADLAB PRO. (2017) Assessment of current AD training practices. Versión electrónica: $<$ https://www.adlabpro.eu/wp-content/uploads/2017/12/20170608_uam_iol_ report.pdf>

ADLAB. (s.f.) Audio Description: Lifelong Access for the Blind. Versión electrónica: $<$ http://www.adlabproject.eu/Docs/ADLAB\%20Infosheet.pdf>

Álvarez de Morales Mercado, Cristina. (2017) "Didáctica de la traducción accesible en el turismo y su aplicación en enseñanzas de posgrado." Revista Digital de Investigación en Docencia Universitaria 11:2, pp. 223-236.

BASICH Peralta, Kora Evangelina; Ana Gabriela Guajardo MarTínez \& Miguel Ángel LEMUS. (2009) "Developing audio description competencies as part of a translation education program." Revista Virtual Plurilinkgua 5:1, pp. 1-12. 
CAmbeiro Andrade, Eva \& María Quereda Herrera. (2007) "La audiodescripción como herramienta didáctica para el aprendizaje del proceso de traducción." En: Jiménez Hurtado, Catalina (ed.) 2007. Traducción y accesibilidad: subtitulación para sordos y audiodescripción para ciegos: nuevas modalidades de Traducción Audiovisual. Frankfurt am Main: Peter Lang, pp. 273-287.

Cerezo Merchán, Beatriz. (2013) "La formación en Traducción Audiovisual en España: Un estudio de caso empírico-descriptivo." Trans. Revista de Traductología 17, pp. 167-183.

DíAz CinTAS, Jorge. (2006) Competencias profesionales del subtitulador y el audiodescriptor. Leganés, Madrid: CESyA. Versión electrónica: <http://www.cesya. es/sites/default/files/documentos/ informe_formacion.pdf>

FrYer, Louise. (2016) An Introduction to Audio Description. Londres: Routledge.

GonzÁlez Davies, María. (2004) Multiple Voices in the Translation Classroom. Ámsterdam: John Benjamins Publishing.

HuERTAS BARROS, Elsa. (2013) La competencia interpersonal en la formación de traductores en España: un estudio empírico-descriptivo del trabajo colaborativo durante la primera etapa de formación en Traducción e Interpretación. Granada: Universidad de Granada. Tesis doctoral inédita.

Johnson, David W. \& Roger T. Johnson. (2017) Cooperative learning. Versión electrónica: <https://webcache.googleusercontent.com/search?q=cache:gKff5cCHOAIJ:https://congresoinnovacion.educa.aragon.es/documents/48/ David_Johnson.pdf $+\& \mathrm{~cd}=1 \& \mathrm{hl}=\mathrm{en} \& \mathrm{ct}=\mathrm{clnk} \& \mathrm{gl}=\mathrm{es} \& \mathrm{client}=$ firefox-b-ab $>$

Johnson, David W.; Roger T. Johnson \& Edythe Johnson HolubeC. (1994) New Circles of Learning: Cooperative Learning in the Classroom and School. Alexandria, Virginia: Association for Supervision and Curriculum Development.

KIRALY, Donald. (2003) "From Teacher-centred to Learning-centred Classrooms in Translator Education: Control, Chaos or Collaboration?" En: Pym, Anthony; Fallada, Carmina; Biau, José Ramón \& Orenstein, Jill (eds.) 2003 Innovation and E-Learning in translation training: Reports on Online Symposia. Tarragona: Universitat Rovira i Virgili, pp. 27-31.

Kiraly, Donald. (2014) A Social Constructivist Approach to Translator Education. Empowerment from Theory to Practice. Londres: Routledge.

LEIGH SMITH, Barbara \& Jean MACGREGOR. (1992) "What is collaborative learning?" En: Goodsell, Anne; Maher, Michelle; Tinto, Vincent; Leigh Smith, Barbara \& MacGregor, Jean 1992 Collaborative Learning: A Sourcebook for Higher Education. University Park, Pennsylvania: National Center on Postsecondary Teaching, Learning, and Assessment. pp. 10-30.

MARTínEZ MARTínEZ, Silvia. (2012) "La audiodescripción (AD) como herramienta didáctica: Adquisición de la competencia léxica.” En: Cruces Collado, Sara; Maribel del Pozo Triviño; Ana Luna Alonso; Alberto Álvarez Lugrís (eds.) 2012. Traducir en la Frontera. Granada: Atrio, pp. 87-102. 
MARTÍNEZ SierRA, Juan José. (ed.) (2012) Reflexiones sobre la traducción audiovisual. Tres espectros, tres momentos. Valencia: Universitat de València.

MARZÀ IBÁÑEZ, Anna. (2010) "Evaluation Criteria and Film Narrative. A Frame to Teaching Relevance in Audio Description." Perspectives: Studies in Translatology, 18:3, pp. 143-153

Matamala, Anna. (2006) "La accesibilidad en los medios: aspectos lingüísticos y retos de formación." En: Sociedad, integración y televisión en España. Madrid: Laberinto, pp. 293-306.

Matamala, Anna \& Pilar ORERo. (2007) "Designing a course on Audio Description: main competences of the future professional." Linguistica Antverpiensia, New Series 6, pp. 329-344.

NAVARRETE, Francisco Javier. (1997) "Sistema AUDESC, el arte de hablar en imágenes." Integración 23, pp. 70-75.

Orero, Pilar. (2005a) "Audio Description: Professional Recognition, Practice and Standards in Spain." Translation Watch Quarterly 1, pp. 7-19.

Orero, Pilar. (2005b) "La inclusión de la accesibilidad en comunicación audiovisual dentro de los estudios de traducción audiovisual." Quaderns. Revista de traducció 12, pp. 173-185.

Remael, Aline \& Gert Vercauteren. (2007) "Audio Describing the Exposition Phase of Films. Teaching Studentts What to Choose." TRANS: Revista de Traductología 11, pp. 73-94.

REYES, María Paloma E. (2007) La introducción de la audiodescripción como herramienta didáctica en el aula de traducción. Granada: Universidad de Granada, Departamento de Traducción e Interpretación.

Rica Peromingo, Juan Pedro. (2016) Aspectos lingüísticos y técnicos de la traducción audiovisual (TAV). Frankfurt am Main: Peter Lang.

SNYDER, Joel. (2007) "Audio Description: The Visual Made Verbal." The International Journal of the Arts in Society: Annual Review 2:2, pp. 99-104.

SNYDER, Joel. (2008) "Audio description: The visual made verbal." En: Díaz Cintas, Jorge (ed.) 2008. The Didactics of Audiovisual Translation. Ámsterdam: John Benjamins Publishing Company, pp. 191-198.

SNYDER, Joel. (2014) The Visual Made Verbal: A Comprehensive Training Manual and Guide to the History and Applications of Audio Description. Indianápolis: Dog Ear Publishing.

TALAVÁN, Noa. (2018) "Traducción audiovisual y aprendizaje del español como L2: el uso de la audiodescripción.” Journal of Spanish Language Teaching 4:2, pp. 168-180.

Talaván, Noa; José Javier Ávila-Cabrera \& Tomás Costal. (2016) Traducción y accesibilidad visual. Barcelona: UOC.

Talaván, Noa.; Antonio Pareja-Lora \& José Javier Ávila-Cabrera. (2014) El proyecto RECORDS: uso de la audiodescripción con fines didácticos en las clases 
de inglés como segunda lengua. Versión electrónica: <https://www.researchgate. net/profile/Maria_Jordano_de_la_Torre/publication/301683312_El_proyecto_ RECORDS_uso_de_la_audiodescripcion_con_fines_didacticos_en_las_ clases_de_ingles_como_segunda_lengua/links/5721d9ea08ae5c4373abfc13/ El-proyecto-RECORDS-uso-de-la-audiodescripcion-con-fines-didacticos-enlas-clases-de-ingles-como-segunda-lengua.pdf?origin=publication_detail> Vermeulen, Anna \& Ana IbáÑEZ Moreno. (2013) "Audio description as a tool to improve lexical and phraseological competence in foreign language learning." En: Tsagari Dina \& Floros Georgios (eds.) 2013. Translation in language teaching and assessment. Newcastle: Cambridge Scholar Press, pp. 45-61.

\section{BIONOTAS / BIONOTES}

NuRIA MENDOZA es actualmente estudiante del programa de doctorado de Traducción y Estudios Interculturales en la Universidad Autónoma de Barcelona. Ha trabajado desde 2004 en la Universidad Nebrija, donde coordina su centro de lenguas. Allí es profesora de Traducción Audiovisual y Accesibilidad para los estudiantes de Traducción y Lenguas Modernas, así como de inglés como lengua extranjera para los estudiantes de grado. Licenciada en Filología Alemana por la Universidad Complutense de Madrid, posee el Máster de Traducción Audiovisual, Localización, Subtitulación y Doblaje por la Universidad de Cádiz/ISTRAD, y el Máster Europeo de Traducción Audiovisual por la Universidad de Parma.

NuRIA MendozA is currently a PhD student at the Universitat Autònoma de Barcelona. Since 2004 she has been working at the Universidad Nebrija, where she has been coordinating the Language Centre since 2009. She has also taught Audiovisual Translation there for the Modern Languages and Translation students. She holds a BA in German Studies from the Universidad Complutense de Madrid, a MA in Audiovisual Translation, Localization, Subtitling and Dubbing from the Universidad de Cádiz/ISTRAD and a European MA in Audiovisual Translation from the Parma University (Italy).

ANNA MATAMALA, licenciada en Traducción e Interpretación (UAB) y doctora en Lingüística Aplicada (UPF), es profesora titular de universidad en la Universitat Autònoma de Barcelona e investigadora principal del grupo TransMedia Catalonia. Ha participado en múltiples proyectos de investigación sobre traducción audiovisual y accesibilidad, así como en la organización de congresos internacionales (M4ALL, ARSAD). Ha publicado en revistas como Meta, 
Translator, Perspectives, Babel y Translation Studies. Actualmente desarrolla también trabajos de estandarización. Más información: gent.uab.cat/amatamala Anna Matamala, BA in Translation (UAB) and PhD in Applied Linguistics (UPF), is an associate professor at Universitat Autònoma de Barcelona (Barcelona). Currently leading TransMedia Catalonia, she has participated and led projects on audiovisual translation and media accessibility. She has taken an active role in the organisation of scientific events (M4ALL, ARSAD), and has published in journals such as Meta, Translator, Perspectives, Babel, Translation Studies. She is currently involved in standardisation work. More information: gent.uab.cat/amatamala 
